\title{
Subclinical infection in leprosy - its detection and control by fluorescent leprosy antibody absorption (FLA-ABS) test
}

\author{
M ABE, T OZAWA, F MINAGAWA \& Y YOSHINO \\ National Institute for Leprosy Research, Higashi-murayama-shi, Tokyo, \\ Japan
}

The fluorescent leprosy antibody absorption (FLA-ABS) test was used for detecting subclinical leprosy infection in the inhabitants in the Miyako Islands which were known as leprosy hyperendemic areas in Japan. One hundred and twenty-six of 1,559 schoolchildren and 68 of 571 adults had suspicious neural symptoms such as the enlargement of auricular and/or ulnar nerve(s) without sensory loss. The FLA-ABS test was positive in $90(71.4 \%)$ of 126 schoolchildren with the enlargement of peripheral nerve and in 13 (14.1\%) of 92 children without any clinical signs. In adults, similar percentages, $66.2 \%(45 / 68)$ and $16.9 \%(23 / 136)$ were obtained. Therefore, a correlation between the FLA-ABS test and the neural symptom is significant statistically in both schoolchildren and adults. Serological specificity of these positive reactions was checked by testing for cross-reactivity with the other mycobacteria. Only 16 out of 183 positive sera showed some cross-reactions. After additional absorption of the sera with the cross-reacting bacteria, positive reactions against $M$. leprae were not affected at all. On the other hand, the FLA-A $\bar{B} S$ test was negative in all of the healthy blood donors and the students of nurse school and in 23 of 24 patients with the other skin diseases in leprosy nonendemic areas. Therefore, the percentage of positive FLA-ABS test is considered to represent the rate of subclinical leprosy infection. The lepromin test with the Dharmendra's antigen was conducted on the schoolchildren for selecting the individuals with low or no resistance against leprosy. Among 217 schoolchildren examined simultaneously with this and FLA-ABS tests, 58 showed the both positive reactions. The enlargement of peripheral nerve was found in 36 of these cases. The other 30 children showed positive FLAABS test, while negative or doubtful Fernandez' reaction. The neural symptom was found in a half number of these cases. It was suggested that these children should receive priority to vaccination for the prophylaxis of leprosy. 


\section{Introduction}

The most urgent and important requirements for both epidemiology and prophylaxis of leprosy are to detect subclinical infection in the individuals with low or no resistance against $\underline{M}$. leprae and to treat them before the appearance of overt symptoms of leprosy. Although subclinical infections in the household and occupational contacts with leprosy have been reported by many investigators using clinical (1), bacteriological (2,3) and immunological (4-8) observations, the similar infections in general inhabitants of leprosy endemic areas have not been clarified yet, because the methods used so far were not so highly specific for leprosy as suited to that purpose. As reported previously (9), the fluorescent leprosy antibody absorption (FLA-ABS) test proved to be highly sensitive and specific for leprosy and useful for detecting subclinical infection with M. leprae in household contacts and in schoolchildren with the suspicious symptoms. Therefore, this test was applied to a leprosy survey in the most endemic area in Japan and the results obtained by this test alone or by combining with the lepromin test are discussed in this paper from immunological and epidemiological points of view.

Materials and methods

In a period of 1978-80, yearly leprosy surveys were carried out on schoolchildren and adults in three villages (F, I and N) of the Miyako Islands, Okinawa. The sera for FLA-ABS test were collected from the registered leprosy cases, household contacts and the cases with suspicious symptoms such as depigmentation of the skin or the enlargement of peripheral nerve without sensory loss. The control sera were collected at random from the clinically healthy persons with the same sex and age as those with the symptoms. All of the sera were brought on ice to our laboratory and stored at $-20^{\circ} \mathrm{C}$ until tested.

The technics of FLA-ABS test was the same as those described previously (9). An additional absorption of the serum was carried out as follows: $0.05 \mathrm{ml}$ of the serum was mixed with $0.05 \mathrm{ml}$ each of $5 \%(\mathrm{w} / \mathrm{w}) \mathrm{BCG}, 10 \%(\mathrm{v} / \mathrm{v}) \mathrm{M}$. vaccae and 10 or $20 \%(\mathrm{v} / \mathrm{v})$ another mycobacterium, and the serum was diluted to $1: 10$ by adding $0.3 \mathrm{ml}$ of diluent $\mathrm{A}$ (0.02\% cardiolipin-lecithin in PBS). For the additional absorption with $\mathrm{M}$. $\quad 0.1 \mathrm{ml}$ of absorbed serum was mixed with the pellet after centrifugation(at 10,000 rpm for 5 minutes) of the suspension containing a known number of bacilli. The mixture was diluted to $0.4 \mathrm{ml}$ with the diluent $\mathrm{B}(\mathrm{O} .1 \%$ bovine serum albumin in dilent $\mathrm{A})$ and incubated at $37^{\circ} \mathrm{C}$ for 30 minutes. After re-centrifugation to remove bacilli, the supernatant was used immediately for the test.

The Dharmendra's antigen was prepared from the autoclaved tissues of lepromatous patients according to the method described by Dharmendra (10) and standardized by cutaneous reactions in 
guinea pigs sensitized with BCG (11). The becterial count of this antigen was $22.3 \mathrm{million} / \mathrm{ml}$. The lepromin test was carried out as follows: $0.1 \mathrm{ml}$ of the Dharmendra's antigen was injected intracutaneously into a forearm and the diameter of Fernandez reaction was read at $48 \mathrm{th}$ hour after the injection. The grade of positive reaction was expressed by the reading criteria recommended at the 7 th International Congress of Leprology (12): 0-4 mm are negative $(-)$, 5-9 mm are doubtful (士), 10-14 mm are weak positive(1+), 15-19 $\mathrm{mm}$ are moderate positive(2+) and $20 \mathrm{~mm}$ or more are strong positive $(3+)$. In order to avoid any trouble due to ulceration after strong reaction, the lepromin test was not carried out in the schoolchildren who responded strongly to PPD when tested in May 1930. At the same time, almost all of PPD-nagative children were voccinated with BCG.

$\underline{\text { Results and discussion }}$

The percentages of neural and dermal symptoms in the schoolchildren are shown in Table 1 . The enlargement of auricular nerve was found in 120 of 126 children with neural symptoms.

Table 1

Percentage of neural and dermal symptoms in schoolchildren

\begin{tabular}{|c|c|c|c|c|c|c|}
\hline School & Sex & $\begin{array}{l}\text { No. of } \\
\text { examinee }\end{array}$ & $\begin{array}{c}\text { Neural } \\
\text { No. }\end{array}$ & $\begin{array}{c}\text { symptom } \\
(\%)\end{array}$ & $\begin{array}{c}\text { Dermal } \\
\text { No. }\end{array}$ & $\begin{array}{c}\text { symptom } \\
(\%)\end{array}$ \\
\hline \multirow[t]{3}{*}{ Primary } & Boy & 429 & 27 & $6.3)$ & 9 & $(2.1)$ \\
\hline & Girl & 470 & 23 & 4.9) & 10 & $(2.1)$ \\
\hline & Total & 899 & 50 & 5.6) & 19 & $(2.1)$ \\
\hline \multirow[t]{3}{*}{ Middle } & Boy & 331 & 58 & $(17.5)$ & 8 & $(2.4)$ \\
\hline & Girl & 329 & 18 & 5.5) & 3 & $(0.9)$ \\
\hline & $\overline{\text { Total }}$ & 660 & 76 & $(11.5)$ & 11 & $(1.7)$ \\
\hline
\end{tabular}

The enlargement of ulnar nerve was found in 10 children, of which 4 were complicated with the enlargement of auricular nerve. These neural symptoms were more frequent in the middle school boys than in the girls. Such a difference was not found in the primary schoolchildren. One girl in primary school and two girls in middleschool were the registered leprosy cases. Each two children in the both schools had a history of household contact with leprosy. These cases are included in the group with dermal symptoms. However, the percentage of dermal symptoms showed no significant difference according to sex and school.

The percentages of neural and dermal symptoms in adults are shown in Table 2. The enlargement of ulnar nerve was found in 45 adults, while that of auricular nerve was found in 34 adults. The percentage of neural symptoms was generally higher in male than in female and the difference was more apparent in higher aged people. Four cases with a history of household contact with leprosy are 
Table 2

Percentage of neural and dermal symptoms in adults

\begin{tabular}{|c|c|c|c|c|c|c|}
\hline Age & Sex & $\begin{array}{l}\text { No. of } \\
\text { examinee }\end{array}$ & $\begin{array}{c}\text { Neural } \\
\text { No. }\end{array}$ & $\begin{array}{c}\text { symptom } \\
(\%)\end{array}$ & $\begin{array}{c}\text { Dermal } \\
\text { No. }\end{array}$ & $\begin{array}{c}\text { symptom } \\
(\%)\end{array}$ \\
\hline \multirow[t]{2}{*}{$20-39$} & Male & 33 & 4. & $(12.1)$ & 1 & $(3.0)$ \\
\hline & Female & 40 & 2 & $5.0)$ & 0 & (0) \\
\hline \multirow[t]{2}{*}{$40-59$} & Male & 50 & 6 & $(12.0)$ & 2 & $(4.0)$ \\
\hline & Female & 184 & 14 & $(7.6)$ & 1 & $(0.5)$ \\
\hline \multirow[t]{2}{*}{$60-$} & Male & 85 & 29 & 34.1 & 2 & $(2.4)$ \\
\hline & Female & 179 & 13 & $7.3)$ & 3 & $(1.7)$ \\
\hline \multirow{2}{*}{ Total } & Male & 168 & 39 & $(23.2)$ & 5 & $(3.0)$ \\
\hline & Female & 403 & 29 & $(7.2)$ & 4 & $(1.0)$ \\
\hline
\end{tabular}

included in the group with dermal symptoms. There was no difference in the percentage of dermal symptoms according to sex and age.

The results of FLA-ABS test in schoolchildren with or without symptoms are shown in Table 3. The highest percentage of positive reaction was seen in the children with neural symptoms, the second in the children with dermal symptoms and the lowest in the children without any symptoms. The $X^{2}$ test indicates that the differences are statistically significant. The results of FLA-ABS tests in adults are shown in Table 4. The difference in the percentage of

Table 3

Symptoms and FLA-ABS tests in schoolchildren

\begin{tabular}{|c|c|c|c|}
\hline Sym ptom & Positive & $\begin{array}{r}\text { FLA-ABS Test } \\
\text { Negative }\end{array}$ & Total \\
\hline Neural & $(71.4)$ & $(28.6)$ & 126 \\
\hline Dermal & $(40.0)$ & $(60.0)$ & 30 \\
\hline None & (14.1) & $(85.9)$ & 92 \\
\hline Total & $(46.4)$ & $(53.6)$ & 248 \\
\hline
\end{tabular}

Table 4

Symptoms and FLA-ABS tests in adults

\begin{tabular}{lcccccc}
\hline & \multicolumn{5}{c}{ FLA-ABS Test } \\
Symptom & Positive & $(\%)$ & Negative & $(\%)$ & Total \\
\hline Neural & 45 & $(61.0)$ & 23 & $(39.0)$ & 68 \\
Dermal & 2 & $(16.9)$ & 113 & $(83.1)$ & 93 \\
None & 23 & $(16)$ & 143 & $(67.1)$ & 213 \\
\hline Total & 70 & $(32.9)$ & $P<0.001$ & &
\end{tabular}

positive reaction according to the presence or absence of symptoms was also significant statistically.

These results suggest that the enlargement of auricular and ulnar nerves without sensory loss may be subclinical signs caused by $\underline{M}$. leprae infection. Nearly 30-40\% of persons with neural symp- 
toms were negative in FLA-ABS test. This fact may be explained by insufficient production of antibodies against a small number of bacilli infected in the nerve. Alternatively, these persons might respond with cell-mediated immunity (CMI), as suggested by the previous findings (9) that the FLA-ABS test was negative in $20 \%$ of the patients with tuberculoid leprosy. On the other hand, dermal symptoms seem to be not characteristic of subclinical leprosy infection, because the frequency of the cases with this symptom showed no significant difference according to sex and age and the percentage of positive FLA-ABS test in these cases was relatively low. The percentage becomes lower if 3 cases with leprosy and 8 household contacts are omitted from this group, because the FLA-ABS test was positive in 3 cases with leprosy and in 5 contacts.

It was noticed that the FLA-ABS test was positive in $14.1 \%$ of schoolchildren and in $16.9 \%$ of adults without any symptoms. Serological specificity of the positive reactions is especially required for the assumption that these persons are also infected subclinically with $\underline{M}$. leprae. Therefore, all of the sera showing positive reaction were checked by testing cross-reactivity with the other mycobacteria as indicated in Table 5. Among the 183 sera tested, only 9 sera from schoolchildren and 7 sera from adults showed one or more cross-reaction(s) with any of these bacilli, but the remaining 167 sera showed no cross-reaction. Both $\underline{M}$. smegmatis and

Table 5

Cross reaction with the other mycobacteria

\begin{tabular}{|c|c|c|c|c|c|c|c|}
\hline \multirow{2}{*}{$\begin{array}{c}\text { Serum } \\
\text { No. }\end{array}$} & \multirow{2}{*}{$\begin{array}{c}\text { FLA-ABS } \\
\text { titer }\end{array}$} & \multirow{2}{*}{$\begin{array}{l}\text { Cross } \\
t .\end{array}$} & \multicolumn{2}{|c|}{ reaction } & with & \multicolumn{2}{|c|}{ Mycobacterium } \\
\hline & & & $\mathrm{k}$. & $\mathrm{m}$. & s. & p. & $\mathrm{a}$. \\
\hline 1031 & 640 & - & - & - & - & - & + \\
\hline 1040 & 640 & + & - & - & - & - & - \\
\hline 1070 & 40 & - & - & - & + & - & - \\
\hline 1071 & 160 & - & + & - & - & - & - \\
\hline 1105 & 640 & - & - & - & + & - & - \\
\hline 1139 & 160 & - & - & - & + & - & - \\
\hline 1192 & 40 & - & - & - & + & - & - \\
\hline 1211 & 160 & - & + & + & + & - & + \\
\hline 1247 & 40 & - & - & - & - & - & + \\
\hline S51 & 40 & - & - & - & - & - & + \\
\hline S84 & 40 & - & + & - & - & - & + \\
\hline S92 & 160 & - & - & - & + & - & - \\
\hline S109 & 40 & + & - & - & - & - & - \\
\hline $\mathrm{N} 102$ & 40 & - & - & + & + & - & - \\
\hline $\mathrm{N} 123$ & 40 & - & - & - & + & - & + \\
\hline $\mathrm{J} 60$ & 640 & - & - & + & + & + & + \\
\hline
\end{tabular}


M. avium were the most frequently cross-reactive with the sera indicated in Table 5. Then, an additional absorption with these mycobacteria was carried out, in order to know whether these positive reactions are caused by $\underline{M}$. leprae-specific antibodies or by the cross-reacting antibodies which have not been absorbed with BCG and M. vaccae. Three representative results in a series of these experiments are shown in Fig. 1 and Fig. 2 .

The serum No. 1211

showed the crossreactions with 4 species of mycobacteria still after the absorption with BCG and M. vaccae. Among these bacteria, M. smegmatis gave the highest antibody titer. After additional absorption with this bacilli, the crossreactions disappeared completely, but the reaction against M. leprae was not influenced at all. The cross-reactions of serum J60 became negative after the absorption with a mixture of $\underline{M}$. marinum, $\underline{M} \cdot-$ smegmatis and M. avium, but the post-absorbed

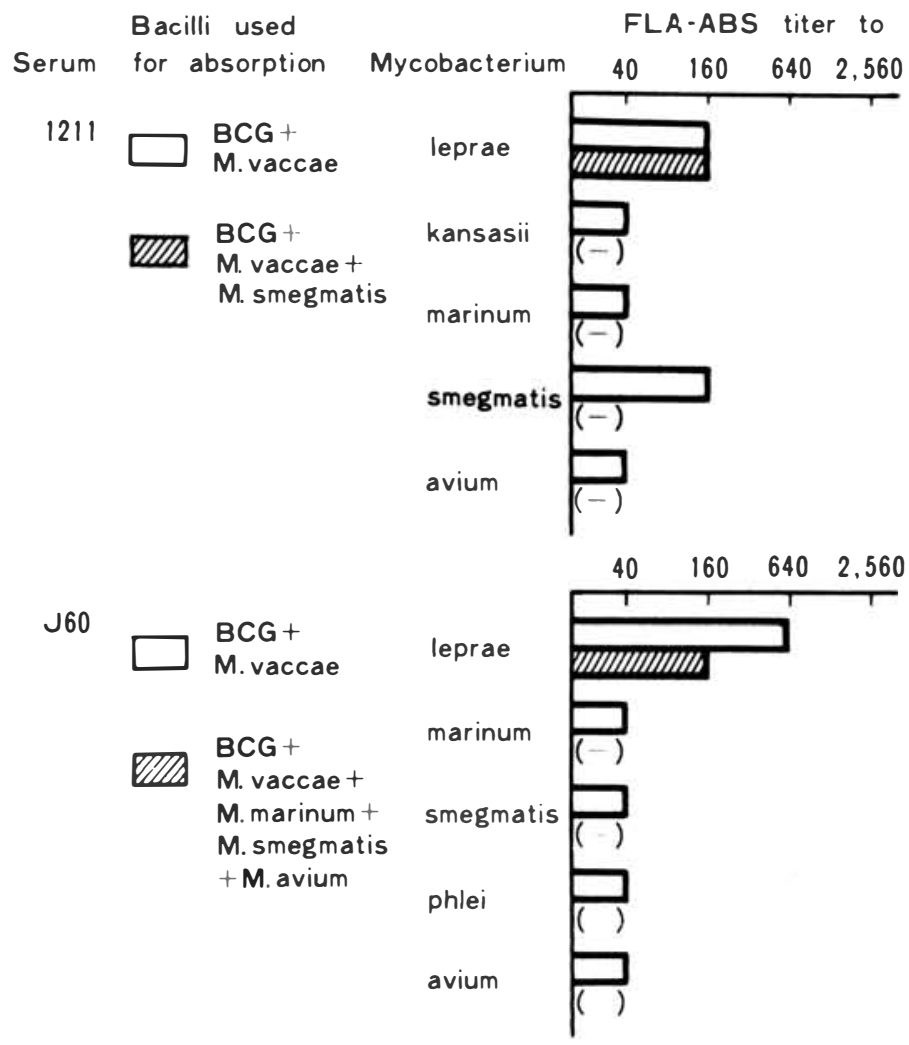
serum was still positive against

M. leprae, though the antibody titer was somewhat reduced. A case in Fig. 2 was a middle school girl with high antibody titers against $\underline{M}$. leprae, $\underline{M}$. smegmatis and $\underline{M}$. avium, and she was later diagnose $\bar{d}$ as having leprosy. After àdditional absorption with $\underline{M}$. $\underline{\text { smegmatis }}$ or $\underline{M}$. avium, the cross-reactions were still positive, though the antibody titer fell significantly. However, the antibody titer to $M$. leprae was not influenced at all by such an additional absorption. On the other hand, when this serum was additionally absorbed with $\underline{M}$. leprae $(A)$, only the reaction against 
M. 1 eprae $(\mathrm{H})$ became

negative. From these results, it was made

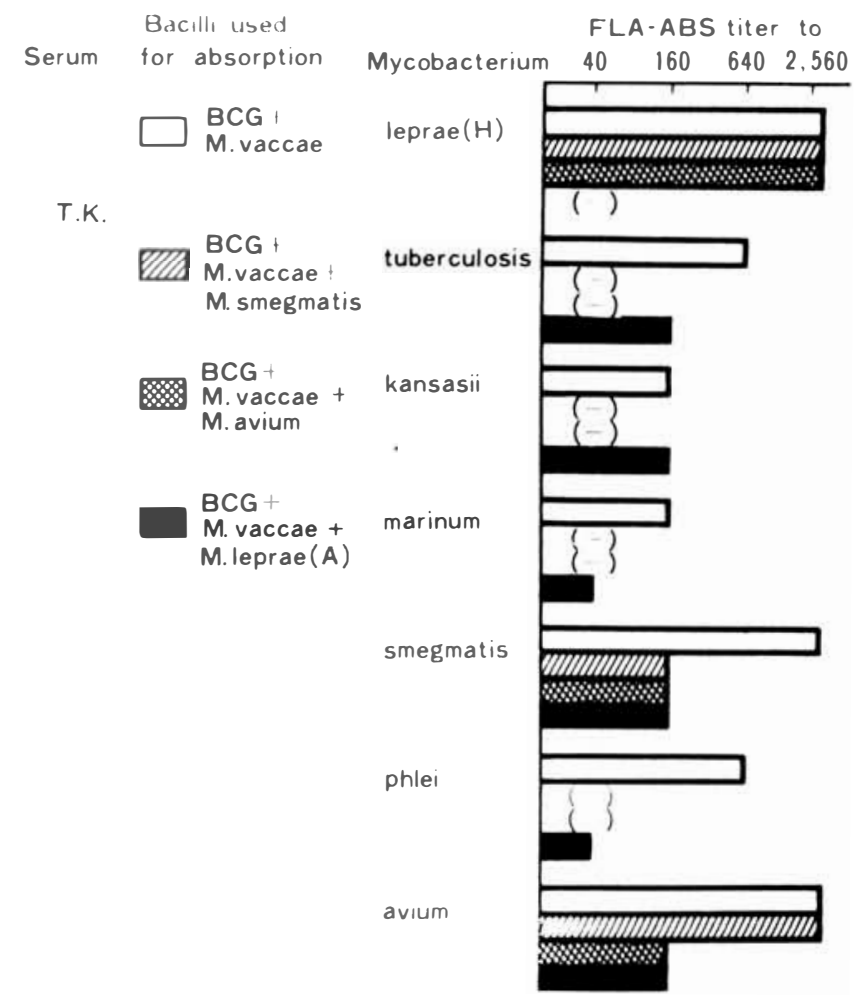
clear that the positive FLA-ABS tests with these sera were caused by $\underline{M}$. lepraespecific antibodies. Another verification of the specificity of this test is the negativeness in non-leprosy cases and in healthy persons living in nonendemic areas. Although this was reported in the previous paper (9), similar results obtained thereafter are shown in Table 6 .
Fig. 2 Verification of specificity by additional absorption (A leprosy case)

Table 6

FLA-ABS test in non-leprosy sera

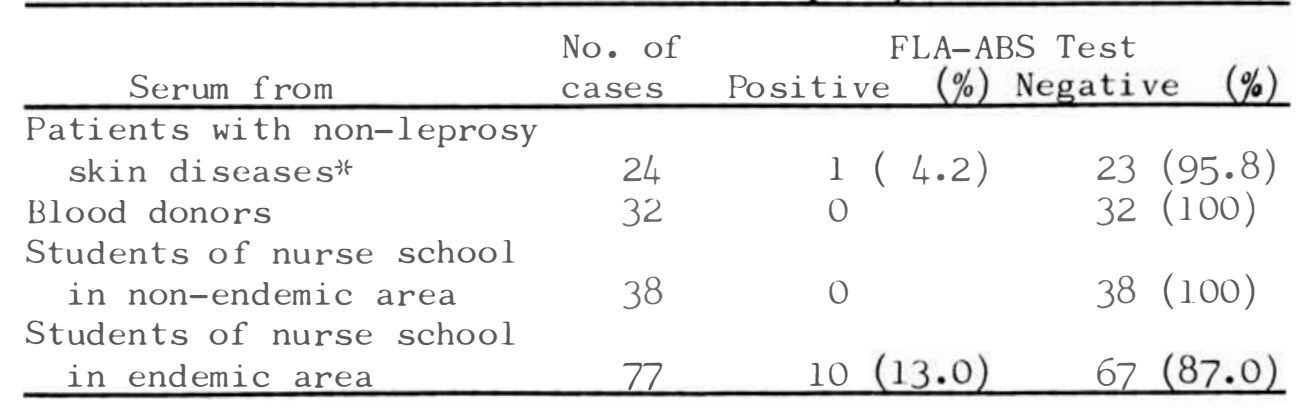

* Two cases with neuropathy, 3 erythema induratum Bazin, 3 dermatitis, 3 psoriasis vulgaris, 4 tumor, 7 collagen diseases, 1 syhilis and 1 erythrodermia. 
Among 24 patients with non-leprosy skin diseases, only one case with neuropathy showed positive result. Healthy blood donors and the students of nurse school in leprosy non-endemic area were all negative. On the contrary, the test was positive in $13 \%$ of the students of nurse school in leprosy-endemic area. This percentage may represent the frequency of subclinical leprosy infection among young people in this area, though their native places are not limited to the Miyako Islands.

Taking this value and those indicated in Table 3 and 4 into account together, a frequency of subclinical leprosy infection in the Miyako Islands is estimated as at least $15 \%$, and this value is just a thousond times larger than the leprosy incidence rate in this area in 1978 (13). This ratio is 5 times larger than that estimated from the survey in the Okinawa Main Island in 1977 (9). Therefore, it is suggested that the higher the incidence of leprosy the more the rate of subclinical infection.

All of the results stated above demonstrate the usefulness of FLA-ABS test for detecting subclinical leprosy infection and the applicability of this test to epidemiological study on leprosy. However, for the prophylaxis of leprosy, we must select the individuals with low or no resistance against leprosy. This is achieved by a combined use of FLA-ABS test with any CMI test. In 1980, such a trial was conducted on the schoolchildren in the same villages of Miyako Islands. The Dharmendra's antigen was used for lepromin test and only the Fernandez' reaction was read, because it was difficult to read the Mitsuda's reaction in this field-servey and the Mitsuda's integral lepromin is known to sensitive the individuals injected with its single test dosis. On the other hand, however, the results of Fernandez' reactions must be discussed from their cross-reactivity in tuberculosis infection, since the most of schoolchildren were tuberculin (PPD)-positive either by natural infection or by BCG-vaccination. As shown in Fig. 3, the percen-

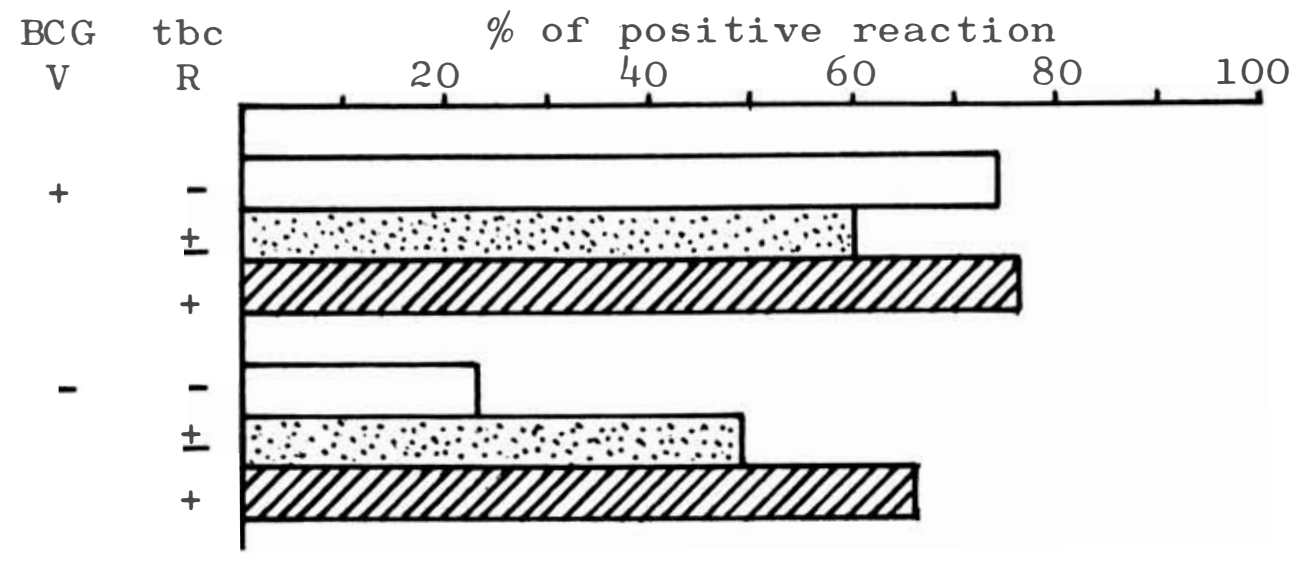

Fig. 3 Percentage of positive Fernandez' reaction in schoolchildren classified by tuberculin reaction (tbc R) and BCG vaccination (V) 
tage of positive Fernandez' reaction in BCG-vaccinated children was nearly the same and independent of the results of tuberculin test. In the children wi thout BCG-vaccination, however, the percentage of positive Fernandez' reaction showed a significant difference according to the results of tuberculin test. This fact is explained by a common antigenicity between tuberculin and Dharmendra's antigen. It was noticed, however, that the Fernandez' reaction was positive in $23.8 \%$ of tuberculin-negative and BCG-unvaccinated schoolchildren and that the reaction was negative or doubtful in $34 \%$ of tuberculin-positive and BCG-unvaccinated children. Accordingly, a correlation between the both skin tests was found to be not so close as we expected.

The results of FLA-ABS test combined with lepromin test are shown in Table 7. The percentage of neural symptom is apparently higher in the FLA-ABS-positive children. The both tests were positive in 36 of 71 cases with neural symptom. Since positive FLAABS test indicates a subclinical infection with $M$. leprae, it is probable that the Fernandez' reaction in these cases is al so an immune response against $\underline{M}$. leprae. Even if the reaction has been induced by any other mycobacterial infection, the cellular mechanism of this delayed hypersensitive reaction may also participate in the destruction of bacilli in vivo. Therefore, the 58 children who

Table 7

Neural symptom in schoolchildren classified

by immunological tests

\begin{tabular}{|c|c|c|c|c|c|}
\hline $\begin{array}{l}\text { FLA- } \\
\text { ABS } \\
\end{array}$ & $\begin{array}{l}\text { Lepro- } \\
\text { min }\end{array}$ & + & $\begin{array}{r}\text { Neural } \\
(\%)\end{array}$ & $\begin{array}{c}\text { symp tom } \\
-\end{array}$ & Total \\
\hline+ & $\overline{+}$ & 36 & $(62.1)$ & $22(37.9)$ & 58 \\
\hline+ & $-\& \pm$ & 15 & $(50.0)$ & $15(50.0)$ & 30 \\
\hline - & + & 9 & $(11.5)$ & $69(88.5)$ & 78 \\
\hline - & $-\& \pm$ & 11 & $(21.6)$ & $40(78.4)$ & 51 \\
\hline To & & 71 & 32.7 & $146(67.3)$ & 217 \\
\hline
\end{tabular}

showed positive reaction in the both tests are considered as having both types of immunity and being in a state of low possibility of leprosy attack. In the other 30 children, the FLA-ABS test was positive but the lepromin test was negative or doubtful. Neural symptom was found in a half number of these cases. They must be carefully followed up or preferably should be vaccinated, because they have been infected with $M$. leprae without the acquisition of CMI to leprosy. A frequency of the individuals in such an immunological status may be used as an index of susceptibility to leprosy. In the schoolchildren shown in Table 7, this index becomes $0.138(=30 / 217)$. If they receive priority to vaccination, this index will be useful for estimating and reducing the scale of vaccination trial in near future. 


\section{Acknowledgement}

This investigation was conducted as a special research project of the Ministry of Health and Wellare and received support from the Immunology of leprosy (IMMLEP) component of the UNDP/World Bank/ WHO Special Programme for Research and Training in Tropical Diseases and from the Japanese Leprosy Panel of the U.S.-Japan Cooperative Medical Science Program. The authors express sincere thanks to all participants in the survey held by the Division of Prophilaxis, Department of Environment and Health, Okinawa Prefecture and to Dr. K. Ohira, National Leprosarium Tama Zensho-en, Dr. T. Saito, National Leprosarium Okinawa Airaku-en and Prof. S. Hidano, Tokyo Women's Medical College for supplying the sera for this study.

\section{References}

1 Yokota T. The observation of the healthy(untainted) children isolated from their leprosy parents, La Lepro, 1954, 23, 147157.

2 Figueredo N, Desai SD. Positive bacillary findings in the skin of contacts of leprosy patients, Int J Lepr, 1950, 18, 59-66.

3 Tayler CE, Elliston EP, Gideon H. Asymptomatic infections in leprosy, Int J Lepr, 1965, 33, 716-727.

4 Yokota T. Mitsuda reaction in children of leprous parents, Nagashima Kiyo, 1954, 1, 4-8.

5 Godal T, Lof gren M, Negassi K. Immune response to M. leprae of healthy leprosy contacts, Int J Lepr, 1972, 40, 24

6 Balina LM, Fliess EL, Bachmann $\overline{A, \text { Cardoma }} \mathrm{JE}$, Gatti JC. Similar alterations of lymphoblastic dedifferentiation in lepromatous leprosy patients and their healthy lepromin-negative consanguineous offspring, Int J Lepr, 41, 7-13.

7 Price MA, Anders EM, Anders RF, Russell DA, Dennis ES. Cellmediated immunologic status of healthy members of families with a history of leprosy, Int J Lepr, 1975, 43, 307-313.

8 Menzel S, Bjune G, Kronwall G. Lymphocyte transformation test in healthy contacts of patients with leprosy, 1, Influence of exposure to leprosy within a household, Int J Lepr, 1979, 47, 138-152.

9 Abe M, Minagawa F, Yoshino Y, Ozawa T, Saikawa K, Saito T. Fluorescent leprosy antibody absorption (FLA-ABS) test for detecting subclinical infection with Mycobacterium leprae, Int J Lepr, 1980, 48, 109-119.

10 Dharmendra. The lepromin test, a review, Lepr Rev, 1947, 18, 92.

11 Maeda M, Nakamura K. Relationship between M. leprae and BCG on the skin reaction (lst report), results on the skin reactions in sensitized guinea pigs, La Lepro, 1965, 34, 294-299. 
12 Transactions of the 7th International Congress of Leprology, 1959, p 464, Tofu Kyokai, Tokyo.

13 Division of Prophilaxis, Department of Environment and Health, Okinawa Prefecture, Present status on leprosy, 1979. 